\title{
Violence and aggression at work
}

Pemberton M. N. ', Atherton G. J. ${ }^{2}$ and Thornhill M. H. ${ }^{3}$

The issue of violence and aggression towards healthcare personnel has received increasing attention over recent years. Surveys indicate that such behaviour does occur in both hospital and community dental settings, although in comparison, many other healthcare workers appear to be at greater risk. Information and advice to prevent and manage such situations, should they occur, are available.

Tmagine the scene. It is a hot Friday 1 afternoon, you are running late, and the extra 'toothache' that you agreed to see is in the chair. The patient has clearly had a few to drink and demands the offending tooth out now. Infection, however, makes local anaesthesia impossible and you offer to drain the abscess and prescribe antibiotics as an initial treatment instead. The patient is clearly unhappy. He repeats his demand for an immediate extraction more aggressively. As you try to explain, he gets up from the chair and comes towards you threateningly...

Unfortunately, aggressive behaviour and violence towards healthcare workers is an increasingly recognised problem. Earlier this year, it was widely reported that a general medical practitioner was stabbed in his surgery by a patient, and a healthcare assistant was severely beaten whilst on hospital grounds, all within the period of a single day. Not surprisingly, such events have led to renewed calls for steps to protect healthcare staff from aggression and violence at work. So are healthcare staff at significant risk of violent behaviour and assault whilst carrying out their professional duties?

\section{Assessing the risk}

The actual prevalence of aggression and violence in healthcare settings is difficult

${ }^{1}$ Consultant in Oral Medicine, ${ }^{2}$ Honorary Dental Surgeon, University Dental Hospital of Manchester, Higher Cambridge Street, Manchester M15 6FH

${ }^{3}$ Professor of Clinical Oral Sciences, Oral Diseases

Research Centre, St Bartholomew's and the Royal

London Hospital School of Medicine and Dentistry, 2

Newark Street, London, E1 2AT

Correspondence to Dr M. N. Pemberton.

REFEREED PAPER

Received 25.04.00; Accepted 08.06.00

(c) British Dental Journal 2000; 189: 409-410.
One survey of general medical practitioners found that over 60 per cent of them had experienced abuse or violence by patients or their relatives over a 12 month period, with almost 20 per cent reporting some sort of abuse at least once a month...

to determine from the literature, as much of the data is anecdotal with differing definitions used of what constitutes aggression and violence. Surveys however, suggest a wide variation in rates in different areas and amongst different groups of patients and staff. For doctors, the literature has been reviewed by Hobbs and Keane ${ }^{1}$, who concluded that the risk of suffering violent injury as a doctor remains low.

Experience of aggressive behaviour and abuse however was more common. One survey of general medical practitioners found that over 60 per cent of them had experienced abuse or violence by patients or their relatives over a 12 month period, with almost 20 per cent reporting some sort of abuse at least once a month, the problem appearing to be worse in inner cities.

\section{Hospital cases}

Violent events are also reported in hospitals. One survey of hospital doctors found that over half had been victims of, or threatened with, violence at work, while 41 per cent of junior doctors in high-risk areas such as accident and emergency (A\&E) departments and psychiatry, reported experience of physical violence.

This issue has also generated much discussion in the nursing literature where, in $\mathrm{A} \& \mathrm{E}$ departments, nurses were the most common victims amongst all the staff present. $^{2}$ Indeed, aggressive behaviour and violence towards nurses led to the Nursing Times and Royal College of Nursing launching the 'Stamp out Violence' campaign in $1998 .^{3}$

\section{Dental statistics}

What about dentistry? A recent BDA survey looked at violence and abuse in general dental practice over a three year period. ${ }^{4}$ This covered a total of 3078 practice staff and found that overall, 80 per cent of practice personnel (dentist or auxiliary) had experienced some type of aggression at work. Auxiliary personnel appeared twice as likely to experience verbal assaults as dentists. There were also 25 incidents of physical assault by a patient or the relative of a patient recorded, with dentists twice as likely as auxiliary staff to experience actual physical violence.

In a recent questionnaire survey of 193 dental hospital clinical personnel, we also asked about the experience of staff regarding aggressive patient behaviour (where they had felt physically threatened) and actual assault over a ten-year period (unpublished data). One hundred and fifty eight replies were received. Forty five percent of staff members reported that they had felt threatened and ten (six per cent) reported that they had been assaulted.

The absolute accuracy of these figures should be viewed with caution as error may easily result from the length of the recall required and the risk of responses 
being drawn from experience outside a dental hospital setting. Nonetheless, it appears that threatening behaviour toward staff does occur in both the dental hospital and the general dental practice setting. Actual physical assault however appears relatively uncommon in comparison with rates reported in other areas of healthcare.

\section{Conclusion}

What are the ramifications? All employers have a general duty under the Health and Safety at Work Act (1974), to ensure as far as reasonably practicable the health, safety and welfare of their employees at work. This duty includes systems to help minimise the possibility of violent incidents and the protection of employees from assault while at work. Practical advice on these issues, including prevention and what

\section{All employers have a general duty...to ensure as far as reasonably practicable the health, safety and welfare of their employees at work.}

to do if intimidated or actually assaulted, are clearly explained and readily available in several publications, including a BDA advice sheet. ${ }^{5-7}$ Dentists, particularly those who employ staff, will find the reading of such material worthwhile.

1 Hobbs F D R, Keane U M. Aggression against doctors: a review. J R Soc Med 1996; 89: 69-72.

2 Jenkins M G, Rocke L G, McNicholl B P, Highes D M. Violence and verbal abuse against staff in accident and emergency departments: a survey of consultants in the UK and the Republic of Ireland. J Accid Emerg Med 1998; 15: 262-265.

3 Coombes R. Violence: the facts. Nurs Times 1998; 94: 12-14.

4 Survey into violence and abuse against general dental practitioners and their staff. London: British Dental Association, 1997.

5 BDA advisory service. Violence at work (advice sheet D14). London: British Dental Association, 1997.

6 Shepherd J. Violence in the dental practice. Dental Business 1997; Nov: 26-29.

7 Shepherd J. Violence in healthcare: a practical guide to coping with violence and caring for victims. Oxford: Oxford University Press, 1994. 